\title{
Multitasking in Corporate Tax Evasion
}

Max Planck Institute for Tax Law and Public Finance

Working Paper 2013 - 05

September 2013

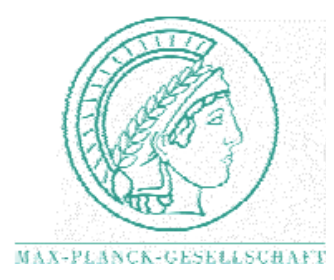

Max Planck Institute for Tax Law and Public Finance

Department of Business and Tax Law

Department of Public Economics

http://www.tax.mpg.de 
Working papers of the Max Planck Institute for Tax Law and Public Finance Research Paper Series serve to disseminate the research results of work in progress prior to publication to encourage the exchange of ideas and academic debate. Inclusion of a paper in the Research Paper Series does not constitute publication and should not limit publication in any other venue. The preprints published by the Max Planck Institute for Tax Law and Public Finance represent the views of the respective author(s) and not of the Institute as a whole. Copyright remains with the author(s).

Max Planck Institute for Tax Law and Public Finance

Marstallplatz 1

D-80539 Munich

Tel: $\quad+498924246-0$

Fax: $\quad+498924246-501$

E-mail: ssrn@tax.mpg.de

http://www.tax.mpg.de 


\title{
Multitasking in Corporate Tax Evasion
}

\author{
Philipp Meyer-Brauns*
}

September 25, 2013

\begin{abstract}
This paper analyzes firms' tax evasion behavior in a principal-agent model with multitasking. A generalist firm-owner hires a specialist tax manager who chooses the quantity as well as the quality of tax evasion. Higher quality lowers the firm's expected fine for tax evasion. In contrast to earlier literature, we find that asymmetric information inside firms may enhance the efficacy of tax enforcement. This occurs because highly sophisticated tax evasion activities are often difficult to understand and assess for the generalist shareholder, who commissions fewer such activities as a result of this informational disadvantage.

Keywords: Corporate Tax Evasion; Principal-Agent Model; Tax Enforcement; Multitasking

JEL Codes: H25; H26; D82
\end{abstract}

* Max Planck Institute for Tax Law and Public Finance, Department of Public Economics, Marstallplatz 1, D-80539 Munich, Germany. Phone: +49 89 24246-5346, Email: Philipp.Meyer-Brauns@tax.mpg.de 


\section{Introduction}

A few fairly recent contributions to the theory of tax evasion have called attention to how principal-agent relationships in firms may alter the analysis of corporate as opposed to individual tax evasion. ${ }^{1}$ They share a common implication regarding tax enforcement policy targeting firms: less is more, for two reasons. First, agency costs ${ }^{2}$ reduce the extent of corporate tax evasion. Second, tax enforcement becomes less effective as a result of agency costs. Allowing for the internal organization of firms, rather than seeing them as individuals, they suggest, both reduces the scope of the problem of corporate tax evasion and makes what is left of it more resistant to enforcement. Because tax enforcement is a costly activity, then, it will be lower where taxpayers enter principal-agent relationships to evade taxes.

In this article, we argue instead that asymmetric information inside corporations enhances the effectiveness of tax enforcement and may therefore be associated with stricter optimal tax enforcement. This is because the previous approach overlooks an important point: tax evasion has various elements, and informational asymmetry affects each of them differently. Indeed, like other executive jobs, corporate tax planning involves not one but a multitude of tasks. For the purpose of this analysis, we focus on two of them: deciding how much to evade and in which way to evade. Put differently, a tax manager determines both the quantity and the quality of tax evasion for the firm. Quality, or how to evade, influences how tax evasion is treated by the tax authority. From the firm's perspective, investing in higher quality is a form of self-insurance: if the firm is audited, higher quality will lower the penalty for evasion. Tax evasion often goes hand in hand with efforts to reduce the potential downside of being fined should an audit occur. In a classic example of such activities ${ }^{3}$, taxpayers in 18th century England are reported to have temporarily bricked up fireplaces as part of their effort to evade hearth taxes. A present-day corporate tax evader may self-insure, for instance, by resorting to more sophisticated tax sheltering techniques or by investing in the justification of a particular legal interpretation of the tax code to prepare for an audit. ${ }^{4}$

\footnotetext{
${ }^{1}$ See Crocker and Slemrod (2005) and Chen and Chu (2005).

${ }^{2}$ In the principal-agent literature, "agency cost" means the cost accruing to a principal of hiring an agent to perform a task instead of performing the task herself.

${ }^{3}$ See Skinner and Slemrod (1985) and Lee (2001).

${ }^{4}$ Indeed, as Lee (2001, p 74) states, referring to Slemrod and Sorum (1984), "outright evasion is rare. Instead, taxpayers plan and do research evasion/avoidance in preparation for possible audits".
} 
Yet, for the same reason a tax authority might not be able to fine high quality tax evasion, a non-specialist firm-owner may have difficulties commissioning it. When evasion schemes are so sophisticated as to be either technically legal or not fully detectable, even upon audit ${ }^{5}$, there is likely a large informational asymmetry between a shareholder and the tax specialist she hires to perform such sophisticated tax evasion.

A principal-agent firm therefore lowers the quality as well as the quantity of tax evasion as a result of agency costs, we find. This may enhance the government's tax enforcement efficacy, because a less sophisticated tax evasion scheme is easier to punish and fully detect upon audit. Unlike earlier contributions, we explicitly model the tax authority as a welfare maximizing player and fully characterize its optimal tax enforcement policy. Because of the effect of agency on the quality dimension of tax evasion, we find that the earlier result of lower optimal tax enforcement due to agency costs is reversed, negated, or at least mitigated. We also provide the condition that decides between these three cases. The present paper is connected to three strands of literature.

First, there is the large economic literature on tax evasion, and in particular the aforementioned literature of corporate tax evasion with agency costs. It is well known since at least Jensen and Meckling (1976) that the separation of ownership and control in corporations systematically influences corporate decision making, as a privately interested manager may not always act in the shareholders' best interest. Yet such agency considerations are largely absent from academic studies of tax evasion. The extensive theoretical literature on tax evasion beginning with Allingham and Sandmo (1972) mainly deals with tax evading individuals, rather than firms ${ }^{6}$, although corporate tax evasion is clearly very relevant both as a way for firms to increase their bottom line and from a policy perspective. ${ }^{7}$ Where corporate tax evasion is explicitly studied, the focus is mostly on firms' external activities in the market rather than on

\footnotetext{
${ }^{5}$ According to Feinstein (1991), typical audits fail to detect the full extent of evasion, as Lee (2001) notes.

${ }^{6}$ For surveys of the literature on individual tax compliance, see Andreoni et al (1998) and Slemrod and Yitzhaki (2002).

${ }^{7}$ Slemrod (2007) estimates that 17 per cent of due corporate income taxes were not paid or collected in the US in 2001. There exist numerous well documented cases of corporations drastically reducing their effective tax rates. See, for instance, Drucker (2010) for the case of Google or Kocieniewski (2011) for the case of General Electric. Corporate tax evasion is a key policy concern for governments around the world, as evidenced by recent OECD (2013) and G20 initiatives (Buergin and Vina 2013).
} 
their internal organization. ${ }^{8}$ Abstracting from agency considerations, this literature therefore seems to be most applicable in the context of self-employment or small, sole-proprietor businesses. When analyzing the tax compliance behavior of widely held corporations, however, additional issues arise because of the separation of ownership and control, as Slemrod (2004) has noted.

The closest work to our analysis is by Crocker and Slemrod (2005), who consider a principal-agent firm with exogenous income and two risk-neutral parties. Their main focus is the relative effectiveness of punishing the agent compared to punishing the principal as a means to curtail tax evasion. Under asymmetric information, they find, punishing a firm-owner is a less effective enforcement policy than punishing the agent or tax manager directly. This is due to the second-best contract that dilutes the impact of punishing the principal under asymmetric information. Agency therefore makes a tax authority's enforcement policy directed at the firm less effective in their model.

Chen and Chu (2005) consider a principal-agent firm, where as in the classic model by Holmström (1979), a risk-averse agent is hired to produce output while the risk-neutral principal may decide whether or not to evade taxes. If only the principal is liable for tax evasion, there is no efficiency loss in production due to tax evasion. If, however, the agent is also liable for tax evasion, the efficiency of the contract between principal and agent decreases, because the agent requires additional ex-ante compensation for conducting tax evasion activities. Unlike Chen and Chu (2005) and in line with Crocker and Slemrod (2005), our paper is not concerned with production efficiency. The agent decides purely on the firm's tax strategy.

Desai and Dharmapala (2006) consider a model in which an agent is hired to perform the risk-free yet costly task of legal tax avoidance for the principal. They posit a complementary relationship between managerial rent diversion and corporate tax avoidance activities and, in the light of corporate scandals such as at Enron, where tax avoidance schemes featured prominently, examine the relationship between high-powered incentive contracts and tax sheltering activities. Desai and Dharmapala (2006) to some extent anticipate an agent performing two tasks, though only one of them pertains to tax avoidance. The other concerns managerial self-dealing for the manager's private gain.

Second, the present analysis encompasses an element of self-insurance against the extent of criminal persecution, an idea pioneered by Ehrlich and Becker

\footnotetext{
${ }^{8}$ For overviews of this literature, see Cowell (2004), Slemrod (2004) and Nur-tegin (2008). For recent contributions, see Bayer and Cowell (2009) and Goerke and Runkel (2011).
} 
(1972). In particular, an agent may exert sophistication effort to reduce a firm's expected punishment by resorting to sophisticated means of tax evasion that legalize these tax reductions or, alternatively, make them harder to detect for tax authorities upon audit. Lee (2001) considers a model of (individual) tax evasion with self-insurance, though not in a principal-agent setting. Biswas et al. (2012) analyze a principal-agent model of corporate tax evasion in which a "gatekeeper" must be hired when evading taxes. The gatekeeper's effort, observable to the principal, determines firm's probability of being audited; however, the principal's (costless) choice of the amount of tax evasion is not part of the contract, and the focus is on symmetric information between principal and agent. Neither model analyzes the situation examined in the present paper, where a tax specialist agent is hired by a generalist firm-owner to determine both the level and the quality of a firm's tax evasion activities, which is arguably closest to what real-world tax specialists hired in such a context do.

Finally, since the tax manager multitasks to determine a firm's overall tax evasion profile, this paper also builds on the multitasking principal-agent literature started by Holmström and Milgrom (1991). Multitasking models have been used to analyze a wide variety of situations in which various aspects of the agent's job are measurable to different extents, such as teacher pay (Holmström and Milgrom 1991) or the provision of quality by regulated firms (Laffont and Tirole 1991). A survey of the literature on multitask principal agent problems is provided by Dewatripont et al (2000). In particular, we employ a multitasking adaptation of the the widely used linear-exponential-normal (LEN) model analyzed in the seminal work of Holmström and Milgrom (1987). A canonical version of this model is presented for instance in Bolton and Dewatripont (2005).

Summing up, the main divergence from the related theoretical literature is twofold: agents multitask over different elements of corporate tax evasion activity, and the tax authority is explicitly featured as a welfare-maximizing player.

It should also be noted that a number of recent studies in accounting research have provided empirical evidence showing that corporate governance characteristics matter for a firm's tax strategy. Armstrong et al (2012) find evidence that tax directors are provided with incentives to reduce the firm's effective tax rate. Moreover, Dyreng et al (2010) show that individual executives significantly impact a firm's tax planning activities. Minnick and Noga (2010) conclude that "[corporate] governance plays an important role in tax management". A recent survey of empirical studies concerning corporate governance and corporate tax 
management is contained in Hanlon and Heitzman (2010).

The remainder of this article is organized as follows. Section 2 introduces the formal model and section 3 presents the analysis of the model. In particular, section 3.1 describes the contractual relationship between firm-owner and tax manager, while section 3.2 derives and characterizes the tax authority's optimal tax enforcement policy. Section 4 concludes.

\section{Model}

We consider a corporate tax evasion game with three players: the tax authority $G$, a firm-owner or principal $P$, and a tax manager or agent $A$. The tax authority chooses a tax enforcement policy ${ }^{9}$ to maximize a social welfare criterion. Given this policy and several exogenous factors described below, a firm-owner may contract with a tax specialist to evade taxes in the following manner.

The principal hires an agent to reduce the firm's tax burden. The agent can exert effort along two dimensions, the quantity and quality of tax evasion.

The quantity effort $e_{R} \in \mathbb{R}_{0}^{+}$represents the tax manager's work toward claiming illegal tax reductions for the firm. It reduces the firm's taxable income by underreporting profits and so increases the firm's expected net profit. Effort $e_{R}$ reduces the firm's taxable income by

$$
R=e_{R}+\epsilon_{R}
$$

The principal cannot observe the effort $e_{R}$, but only the total reductions $R$ of taxable income. $\epsilon_{R}$ is a normally distributed noise term with zero mean and variance $\sigma_{R}^{2}$, so $\epsilon_{R} \sim N\left(0, \sigma_{R}^{2}\right)$. Since the reductions $R$ constitute illegal tax evasion, they are punishable if detected.

However, the agent may also exert the quality effort $e_{S} \in \mathbb{R}_{0}^{+}$. Doing so reduces the firm's expected fine by finding sophisticated legal ways of avoiding taxes that protect the firm's tax reductions from punishment by the authority. Effort $e_{S}$ produces a level $S$ of sophistication given by

$$
S=e_{S}+\epsilon_{S}
$$

\footnotetext{
${ }^{9}$ In line with the previous literature, the focus of this paper is on the choice of the optimal tax enforcement policy, rather than the optimal tax rate $\tau$.
} 
As before, the principal cannot observe the effort $e_{S}$ but only the realized level of sophistication $S$, and the noise term $\epsilon_{S}$ follows $\epsilon_{S} \sim N\left(0, \sigma_{S}^{2}\right)$.

The enforcement process that combines detection probability and fines for evasion is characterized by the government's enforcement policy parameter $\gamma \in$ $[0,1]$. An amount $R$ in tax reductions will be punished with an expected fine $\gamma(R-S)$. That is, a potential fine will be assessed only on the amount of claimed reductions not covered by sophisticated means, namely the remaining level of illegal tax evasion $R-S$. $e_{S}$ therefore represents a form of self-protection effort against punishment. The random components are independently distributed, so $\operatorname{Cov}\left(\epsilon_{R}, \epsilon_{S}\right)=0$.

\section{The tax manager}

The tax manager $A$ chooses the effort levels $e_{R}$ and $e_{S}$ and has constant absolute risk averse preferences. His utility function is given by

$$
U=-e^{-\eta\left(w-C\left(e_{R}, e_{S}\right)\right)} .
$$

where $\eta \in \mathbb{R}^{+}$is the agent's Arrow-Pratt measure of absolute risk aversion

$\left(\eta=-\frac{U^{\prime \prime}}{U^{\prime}}\right), w$ is the agent's monetary compensation, and $C$ is the agent's cost of effort, measured in monetary units. Effort cost takes the quadratic form

$$
C\left(e_{R}, e_{S}\right)=\frac{1}{2} e_{R}^{2}+\frac{1}{2} e_{S}^{2} .
$$

Following the widely used assumptions of a linear wage contract, exponential agent utility, and normally distributed errors (LEN-model) based on Holmström and Milgrom (1987), the compensation contract between principal and agent has the linear form

$$
w=\alpha+\beta_{R} R+\beta_{S} S
$$

where $\alpha \in \mathbb{R}_{0}$ is the fixed wage component and $\beta_{R} \in \mathbb{R}_{0}$ and $\beta_{S} \in \mathbb{R}_{0}$ are the incentive components relating to $R$ and $S$ respectively.

The agent accepts the contract if his expected utility from signing the contract (weakly) exceeds the utility of his outside option $\underline{u}$, which for simplicity is normalized to $\underline{u}=-1 .{ }^{10}$

\footnotetext{
${ }^{10}$ Given the assumptions on $U, \underline{u}=-1$ ensures that the agent's reservation certainty equivalent is equal to zero.
} 


\section{The firm-owner}

The firm-owner $P$ is risk neutral and offers a take-it-or-leave-it wage contract $\left(\alpha, \beta_{R}, \beta_{S}\right)$ to the agent. The principal chooses the contract parameters $\alpha, \beta_{R}$, and $\beta_{S}$ to maximize her expected profits

$$
\mathbb{E} \Pi=\mathbb{E}[I-\tau(I-R)-\gamma \tau(R-S)-w] .
$$

Profits have four components: The firm's exogenous gross income $I \in \mathbb{R}^{+}$, the actual tax payment $\tau(I-R)$, where $\tau \in[0,1]$ is the exogenous corporate income tax rate, the expected fine for evasion $\gamma \tau(R-S)$, and the managerial wage $w=\alpha+\beta_{R} R+\beta_{S} S$.

Expected profits are maximized subject to the agent's participation constraint

$$
\mathbb{E}\left[-e^{-\eta\left(w-C\left(e_{R}, e_{S}\right)\right)}\right] \geq \underline{u}=-1
$$

and an incentive compatibility constraint

$$
\left(e_{R}, e_{S}\right) \in \underset{e_{R}, e_{S}}{\arg \max } \mathbb{E}\left[-e^{-\eta\left(w-C\left(e_{R}, e_{S}\right)\right)}\right]
$$

As is common in the principal-agent literature, the participation constraint $(P C)$ ensures that in expectation, the agent is at least as well off when he accepts the contract as when he does not. The incentive compatibility constraint $(I C)$ ensures that the agent's choices of $e_{R}$ and $e_{S}$ are indeed optimal for him.

\section{The tax authority}

The tax authority chooses an enforcement policy $\gamma \in[0,1]$ to maximize expected social welfare $\mathbb{E} W$,

$$
\mathbb{E} W=\lambda \mathbb{E} \Pi+(1-\lambda) \mathbb{E} T .
$$

Expected social welfare $\mathbb{E} W^{11}$ is the weighted sum of the firm's expected profits $\mathbb{E} \Pi$, with weight $\lambda \in[0,1]$, and expected net government revenue $\mathbb{E} T$, with weight $(1-\lambda)$, which is the sum of tax payments $\tau(I-R)$ and fines $\gamma \tau(R-S)$ less enforcement cost $k(\gamma)$, which is assumed to be quadratic and has a cost

\footnotetext{
${ }^{11}$ Note that for the purpose of our analysis, we can exclude the agent's expected utility $\mathbb{E} U$ from the welfare function $\mathbb{E} W$ without loss of generality, because in equilibrium, the agent will always be reduced to his constant outside option by the principal.
} 
parameter $g \in \mathbb{R}_{0}^{+}$

$$
k(\gamma)=\frac{1}{2} g \gamma^{2}
$$

This model therefore contains the case of a (net) revenue maximizing tax authority that is widely analyzed in the tax compliance literature ${ }^{12}$ as a special case in which $\lambda=0$.

\section{Timing}

In the first stage of the game, the tax authority sets a policy ${ }^{13} \gamma \in[0,1]$ given its expectation of tax evasion outcomes $R$ and $S$ as well as the exogenous tax rate $\tau \in(0,1)$ and gross income $I$.

In the second stage, the firm-owner offers a wage contract $\left(\alpha, \beta_{R}, \beta_{S}\right)$ to the tax manager, given the policy $\gamma$, the tax rate $\tau$, and gross income $I$.

The manager then decides whether or not to accept the contract. Upon acceptance, the agent exerts efforts $\left(e_{R}, e_{S}\right)$ in the third stage of the game.

Finally, tax evasion outcomes $R$ and $S$ are realized, the contract is executed, and the wage, tax payment, and potential fines are paid.

\section{Analysis}

We begin with the contractual relationship between firm-owner and tax manager, who may contract to evade taxes given a tax enforcement policy $\gamma \in[0,1]$ previously chosen by the tax authority.

\subsection{Contracting to evade taxes}

\section{First best ${ }^{14}$ benchmark with observable efforts}

As a benchmark case, consider first the situation in which efforts are observable to the principal. The firm-owner will offer a full insurance contract to the tax manager, that is, she offers a fixed wage giving the agent exactly his outside

\footnotetext{
${ }^{12}$ See for instance the survey of the tax compliance literature by Andreoni et al. (1998)

${ }^{13}$ Following the literature on principal-agent models of optimal tax enforcement based on Reinganum and Wilde (1985), we assume that the tax authority can and does commit to its policy choice. For the discourse regarding this assumption, see the surveys by Andreoni et al. (1998) and Slemrod and Yitzhaki (2002).

${ }^{14}$ Note that the term "first best" used here strictly refers to the principal-agent relationship and describes the situation in which efforts are observable by the principal. It does not concern the relationship between the tax authority and either principal or agent.
} 
option while inducing $e_{R}^{F B}$ and $e_{S}^{F B}$ such that

$$
\max _{e_{R}, e_{S}}\left\{I-\tau\left(I-e_{R}\right)-\gamma \tau\left(e_{R}-e_{S}\right)-\frac{1}{2} e_{R}^{2}-\frac{1}{2} e_{S}^{2}\right\} .
$$

The first-best effort levels $e_{R}^{F B}$ and $e_{S}^{F B}$ that solve this problem are given by

$$
e_{R}^{F B}=(1-\gamma) \tau \quad \text { and } \quad e_{S}^{F B}=\gamma \tau .
$$

We see that if enforcement $\gamma$ is increased, the first best effort with respect to the quantity evaded will be lowered, whereas the effort concerning legal quality or sophistication will be higher. This dual effect of enforcement will carry over into the analysis under asymmetric information.

\section{Contracting when efforts are unobservable}

Suppose now that the firm-owner cannot observe the tax manager's effort choices $e_{R}$ and $e_{S}$, but only the realized tax evasion outcomes $R=e_{R}+\epsilon_{R}$ and $S=$ $e_{S}+\epsilon_{S}$. Then the agent is offered a linear incentive scheme $w=\alpha+\beta_{R} R+\beta_{S} S$ as described above. The tax manager now chooses the quantity of evasion effort $e_{R}$ and the quality of evasion effort $e_{S}$ to maximize his expected utility,

$$
\max _{e_{R}, e_{S}} \mathbb{E}\left[-e^{-\eta\left(w-C\left(e_{R}, e_{S}\right)\right)}\right]
$$

The agent's expected utility can be rewritten, using the properties of normally distributed error terms, as ${ }^{15}$

$$
\mathbb{E}\left[-e^{-\eta\left(w-C\left(e_{R}, e_{S}\right)\right)}\right]=-e^{-\eta\left[\alpha+\beta_{R} e_{R}+\beta_{S} e_{S}-\frac{1}{2} e_{R}^{2}-\frac{1}{2} e_{S}^{2}-\frac{\eta}{2}\left(\beta_{R}^{2} \sigma_{R}^{2}+\beta_{S}^{2} \sigma_{S}^{2}\right)\right]}
$$

so that the bracketed term in the exponent is the agent's certainty equivalent compensation,

$$
\alpha+\beta_{R} e_{R}+\beta_{S} e_{S}-\frac{1}{2} e_{R}^{2}-\frac{1}{2} e_{S}^{2}-\frac{\eta}{2}\left(\beta_{R}^{2} \sigma_{R}^{2}+\beta_{S}^{2} \sigma_{S}^{2}\right) .
$$

This is the certain amount of money that makes the agent exactly indifferent between receiving this certain amount and accepting the contract with uncertain payoffs. The agent's certainty equivalent consists of his expected wage $\alpha+\beta_{R} e_{R}+\beta_{S} e_{S}$ less his cost of effort $\frac{1}{2}\left(e_{R}^{2}+e_{S}^{2}\right)$ and a risk premium

\footnotetext{
${ }^{15}$ See Bolton and Dewatripont (2005) for the derivation in the single-task case, from which the dual-task case analyzed here follows by using a similar argument.
} 
$\frac{\eta}{2}\left(\beta_{R}^{2} \sigma_{R}^{2}+\beta_{S}^{2} \sigma_{S}^{2}\right)$, which is due to the unobservability of efforts in combination with the agent's risk aversion. Maximizing the certainty equivalent compensation is mathematically equivalent to maximizing expected utility, so the agent's problem may be written as

$$
\max _{e_{R}, e_{S}}\left\{\alpha+\beta_{R} e_{R}+\beta_{S} e_{S}-\frac{1}{2} e_{R}^{2}-\frac{1}{2} e_{S}^{2}-\frac{\eta}{2}\left(\beta_{R}^{2} \sigma_{R}^{2}+\beta_{S}^{2} \sigma_{S}^{2}\right)\right\} .
$$

The firm-owner, who offers a wage contract characterized by parameters $\alpha, \beta_{R}$, and $\beta_{S}$ to maximize her expected profits therefore solves

$$
\max _{\alpha, \beta_{R}, \beta_{S}}\left\{I-\tau\left(I-e_{R}\right)-\gamma \tau\left(e_{R}-e_{S}\right)-\left(\alpha+\beta_{R} e_{R}+\beta_{S} e_{S}\right)\right\}
$$

subject to

$$
\alpha+\beta_{R} e_{R}+\beta_{S} e_{S}-\frac{1}{2} e_{R}^{2}-\frac{1}{2} e_{S}^{2}-\frac{\eta}{2}\left(\beta_{R}^{2} \sigma_{R}^{2}+\beta_{S}^{2} \sigma_{S}^{2}\right) \geq 0
$$

and

$$
\left(e_{R}, e_{S}\right) \in \underset{e_{R}, e_{S}}{\arg \max }\left\{\alpha+\beta_{R} e_{R}+\beta_{S} e_{S}-\frac{1}{2} e_{R}^{2}-\frac{1}{2} e_{S}^{2}-\frac{\eta}{2}\left(\beta_{R}^{2} \sigma_{R}^{2}+\beta_{S}^{2} \sigma_{S}^{2}\right)\right\}
$$

In other words, the take-it-or-leave-it contract offered by the firm-owner to the tax manager is such that it maximizes the firm's expected after-tax profits while ensuring that the agent accepts the contract by awarding him, in expectation, at least his outside option as described in condition $(P C)$, and it provides incentives that take into account the agent's optimal effort choices, which yields the incentive compatibility constraint $(I C)$. Let us now solve for and characterize the equilibrium contract and effort choices that arise in this setup.

Proposition 1. [Optimal second best contract]

In the unique equilibrium, the contract offered by the firm-owner satisfies

$$
\begin{gathered}
\beta_{R}^{*}=\frac{(1-\gamma) \tau}{1+\eta \sigma_{R}^{2}}, \quad \beta_{S}^{*}=\frac{\gamma \tau}{1+\eta \sigma_{S}^{2}}, \quad \text { and } \\
\alpha^{*}=\frac{1}{2}\left(\eta \sigma_{R}^{2}-1\right) \frac{(1-\gamma)^{2} \tau^{2}}{\left(1+\eta \sigma_{R}^{2}\right)^{2}}+\frac{1}{2}\left(\eta \sigma_{S}^{2}-1\right) \frac{\gamma^{2} \tau^{2}}{\left(1+\eta \sigma_{S}^{2}\right)^{2}},
\end{gathered}
$$


and the equilibrium efforts $\left(e_{R}^{*}, e_{S}^{*}\right)$ exerted by the tax manager are given by

$$
e_{R}^{*}=\frac{(1-\gamma) \tau}{1+\eta \sigma_{R}^{2}} \quad \text { and } \quad e_{S}^{*}=\frac{\gamma \tau}{1+\eta \sigma_{S}^{2}}
$$

Proof. See appendix A.1.

As is common in this type of principal-agent relationship ${ }^{16}$, the second best contract is inefficient because there exists a trade-off between risk and incentives. Optimal risk-sharing would require the risk-neutral principal to bear all risk and hence fully insure the risk averse agent. Because efforts are not observable, however, such a full insurance contract would not provide optimal incentives to the agent. So, in the second best contract, the principal offers incentive components $\beta_{R}^{*}$ and $\beta_{S}^{*}$ based on the observable realizations of $R$ and $S$ as well as a fixed wage $\alpha^{*}$, which is set such that, in expectation, the agent is reduced to his reservation utility, meaning his participation constraint $(P C)$ holds with equality. As can be seen from (3), the agent's tax evasion activities will always comprise some positive level of sophistication in equilibrium, except when there is no tax enforcement at all, i.e. when $\gamma=0$. It also emerges from (3) that when efforts are unobservable, the quantity evaded is lower in expectation than under first best with observable efforts, namely

$$
e_{R}^{*}<e^{F B}=(1-\gamma) \tau
$$

This is a version of the well-known argument that asymmetric information may lead to underprovision of effort compared to the full information case and is a finding first presented in the context of corporate tax evasion by Chen and Chu (2005) and Crocker and Slemrod (2005).

Because the focus of our analysis is on the tax authority's choice of an optimal enforcement policy, let us now examine how the tax authority's enforcement policy $\gamma$ affects equilibrium evasion activities $e_{R}^{*}$ and $e_{S}^{*}$.

Corollary (1). [Effect of enforcement on equilibrium efforts]

Higher enforcement reduces the quantity-of-evasion effort $e_{R}^{*}$, but increases the quality-of-evasion effort $e_{S}^{*}$.

$$
\frac{\partial e_{R}^{*}}{\partial \gamma}<0 \quad \text { and } \quad \frac{\partial e_{S}^{*}}{\partial \gamma}>0
$$

\footnotetext{
${ }^{16}$ See, for instance, Laffont and Martimort (2001).
} 
Proof. Follows directly from (3).

Corollary 1 shows the two effects that tax enforcement has when a form of selfinsurance against potential punishment for tax evasion is available to the firm. On the one hand, higher enforcement decreases, in expectation, the quantity evaded. On the other hand, the legal quality of the firm's tax evasion will rise in response to tougher enforcement. In some sense, the existence of sophisticated means of tax evasion that escape punishment therefore compromises the government's ability to conduct an effective enforcement policy. Stricter enforcement, while reducing the quantity evaded, also drives firms into using more sophisticated means of tax evasion. This dual effect hints at a trade-off the tax authority faces in setting its optimal policy, as we explore in more detail below. Since, in this model, both types of evasion activities are produced in a principal-agent framework, the accuracy of the performance measures $R$ and $S$ used for contracting will impact the effect enforcement has on efforts $e_{R}^{*}$ and $e_{S}^{*}$ exerted in equilibrium, as the following corollary shows.

Corollary (2). [Performance measure accuracy and the effect of enforcement] (i) A higher variance $\sigma_{R}^{2}$ diminishes the (negative) impact of enforcement on the quantity evaded

$$
\frac{\partial}{\partial \sigma_{R}^{2}}\left|\frac{\partial e_{R}^{*}}{\partial \gamma}\right|<0
$$

(ii) A higher variance $\sigma_{S}^{2}$ diminishes the (positive) impact of enforcement on the quality of tax evasion

$$
\frac{\partial}{\partial \sigma_{S}^{2}}\left|\frac{\partial e_{S}^{*}}{\partial \gamma}\right|<0
$$

Proof. See appendix A.2.

Part $(i)$ of Corollary 2 states that when efforts are unobservable, a less accurate performance measure for the quantity effort $e_{R}$ leads to less effective enforcement. This is the analogue in this model of the familiar result from Crocker and Slemrod (2005), which states that because enforcement directed at the principal impacts the agent only indirectly, through a second best wage contract, its impact on tax evasion activities is weakened compared to a situation with observable efforts. There exists, however, a second effect when efforts are unobservable by the principal. This second effect is stated in part (ii) of Corollary 2: A less accurate performance measure for the quality effort $e_{S}$ lowers the 
extent to which stricter enforcement (higher $\gamma$ ) drives up sophistication effort. Because a high variance $\sigma_{S}^{2}$ makes sophistication effort $e_{S}$ costly to incentivize, the principal is less inclined to counter stricter enforcement by commissioning a more sophisticated way of evading taxes than she would be in a first best world with observable efforts. The following section examines how the principal-agent contracting between firm-owner and tax manager characterized here shapes the tax authority's enforcement policy.

\subsection{Optimal enforcement policy}

Consider now the tax authority's problem of choosing an enforcement policy $\gamma \in[0,1]$ to maximize expected social welfare $\mathbb{E} W$. Recall from above that the tax authority's objective function is given by

$$
\mathbb{E} W=\lambda \mathbb{E} \Pi+(1-\lambda) \mathbb{E} T
$$

That is, the tax authority chooses a policy $\gamma$ to maximize a weighted average of expected profits and expected tax revenue.

We proceed to examine the components of the government's objective function (4) in the light of the equilibrium tax evasion contract between firm-owner and tax manager as obtained in Proposition 1.

Expected profits carry the welfare weight $\lambda \in[0,1]$ and are given in the firmowner's maximization problem above. Using the expressions for the tax manager's equilibrium effort choices $e_{R}^{*}$ and $e_{S}^{*}$ from Proposition 1, expected profits may be written as

$$
\mathbb{E} \Pi=(1-\tau) I+\frac{1}{2}(1-\gamma)^{2} \frac{\tau^{2}}{\phi_{R}}+\frac{1}{2} \gamma^{2} \frac{\tau^{2}}{\phi_{S}}
$$

where we defined

$$
\phi_{R}=1+\eta \sigma_{R}^{2} \quad \text { and } \quad \phi_{S}=1+\eta \sigma_{S}^{2} .
$$

In the absence of any evasion activities, the firm's net profits are given by ( 1 $\tau) I$. It follows from (5) that since two non-negative terms are added to $(1-\tau) I$, the firm's expected profits increase due to tax evasion in equilibrium. Also

notice that expected net profits are decreasing in both $\phi_{R}$ and $\phi_{S}$. This means in particular that as the performance measures $R$ and $S$ become less accurate 
( $\sigma_{R}^{2}$ and $\sigma_{S}^{2}$ increase), the firm owner's benefit from tax evasion decreases. This is intuitively convincing: The more costly it is to incentivize tax evasion activities due to difficulties in measuring the agent's performance accurately, the less profitable it is for the principal to do so.

Conversely, expected net tax revenue $\mathbb{E} T$, which includes tax payments and fines less enforcement cost, carries the welfare weight $(1-\lambda)$ and is given by

$$
\mathbb{E} T=\tau\left(I-e_{R}\right)+\gamma \tau\left(e_{R}-e_{S}\right)-\frac{1}{2} g \gamma^{2}
$$

Plugging in the tax manager's equilibrium effort choices $e_{R}^{*}$ and $e_{S}^{*}$, expected tax revenue becomes

$$
\mathbb{E} T=\tau I-(1-\gamma)^{2} \frac{\tau^{2}}{\phi_{R}}-\gamma^{2} \frac{\tau^{2}}{\phi_{S}}-\frac{1}{2} g \gamma^{2} .
$$

Expected tax revenue is lowered by tax evasion activities, as can be seen from (6). Two non-negative terms associated with the two dimensions of tax evasion, quantity and quality, are subtracted from $\tau I$, which is the level of tax revenue absent any tax evasion. In analogy to the case of expected profits, we now find that expected tax revenue increases in $\phi_{R}$ and $\phi_{S}$. The more costly it is to incentivize tax evasion efforts due to agency problems, the less of a dent such activities will make on the public purse. The last term $\frac{1}{2} g \gamma^{2}$ in (6) accounts for the monetary cost of tax enforcement, which is increasing and quadratic in the intensity of tax enforcement.

Combining the equilibrium expressions for expected profits (5) and expected net tax revenue $(6)$, the government chooses $\gamma \in[0,1]$ to maximize

$\lambda I+(1-2 \lambda) \tau I-\frac{1}{2}(2-3 \lambda)(1-\gamma)^{2} \frac{\tau^{2}}{\phi_{R}}-\frac{1}{2}(2-3 \lambda) \gamma^{2} \frac{\tau^{2}}{\phi_{S}}-(1-\lambda) \frac{1}{2} g \gamma^{2}$.

It follows from (7) that if $\lambda<\frac{2}{3}$, tax evasion leads to an overall loss in expected welfare. To see this, note that $\lambda<\frac{2}{3}$ implies $2-3 \lambda>0$; thus, the two terms in (7) associated with the two dimensions of tax evasion negatively impact expected social welfare. So, if tax revenue is a sufficiently important component of social welfare, namely if $\lambda \in\left[0, \frac{2}{3}\right)$, tax evasion is socially harmful. If on the other hand $\lambda>\frac{2}{3}$, that is profits are heavily weighted in social welfare compared to tax revenues, we see from (7) that tax evasion leads to a welfare gain. If $\lambda=\frac{2}{3}$, the effects of tax evasion on profits and on tax revenue exactly cancel each other out and social welfare is not affected by tax evasion. From (7), it 
is seen that for a given policy $\gamma$, the unobservability of efforts diminishes the effects of tax evasion on social welfare. As $\phi_{R}$ and $\phi_{S}$ become very large, social welfare approaches the level it would attain absent any tax evasion activities, as these activities become prohibitively costly to incentivize and equilibrium efforts $e_{R}^{*}$ and $e_{S}^{*}$ approach zero. Let us now consider the tax authority's optimal choice of tax enforcement policy.

Proposition 2. [Tax enforcement policy in equilibrium]

Suppose $\sigma_{S}^{2}>\sigma_{R}^{2}$. Then the equilibrium level of tax enforcement is given by

$$
\gamma^{*}=\left\{\begin{array}{ccc}
\frac{\phi_{S}}{\phi_{S}+\phi_{R}+\frac{(1-\lambda) g}{(2-3 \lambda) \tau^{2}} \phi_{R} \phi_{S}} & \text { if } & \lambda \in\left[0, \frac{2}{3}\right) \\
0 & \text { if } & \lambda \in\left[\frac{2}{3}, 1\right]
\end{array}\right.
$$

Proof. See appendix A.3.

At the optimum, the marginal change in social welfare in response to a change in tax enforcement activity equals the marginal cost of tax enforcement so that the first order condition of the government's problem is satisfied. Proposition 2 shows that if profits are heavily weighted in the social welfare function, namely when $\lambda \in\left[\frac{2}{3}, 1\right]$ so that tax evasion is socially beneficial, the government's optimal policy is to conduct no enforcement at all and set $\gamma^{*}=0$. Intuitively, since enforcement is costly and reduces a socially beneficial activity, it can only be optimal to enforce as little as possible.

The more interesting and relevant case is when tax revenues matter enough to social welfare for tax evasion to be a socially harmful activity. This is the case when $\lambda<\frac{2}{3}$, which we assume in what follows.

Before proceeding to analyze how the principal-agent relationship between firmowner and tax manager influences tax enforcement policy, let us briefly note some properties of the equilibrium enforcement policy that emerge immediately from Proposition 2 and describe the equilibrium effects of the cost of enforcement $g$, the welfare weight $\lambda$, and the tax rate $\tau$.

Unsurprisingly, the optimal enforcement intensity decreases in the cost parameter of enforcement, $g$.

Moreover, the level of enforcement $\gamma^{*}$ is decreasing in the welfare weight $\lambda$, meaning that if profits are a more heavily weighted component of social welfare, optimal enforcement will correspondingly be lower. This follows immediately from the fact that firms benefit from tax evasion. 
Optimal enforcement $\gamma^{*}$ is also increasing in the tax rate $\tau$, suggesting that tax rates and the level of tax enforcement are complementary policy choices.

The main focus of this paper is the effect of the principal-agent relationship inside the firm on the tax authority's enforcement policy choice. We see from Proposition 2 that the equilibrium enforcement intensity is decreasing in $\phi_{R}=$ $1+\eta \sigma_{R}^{2}$ but increasing in $\phi_{S}=1+\eta \sigma_{S}^{2}$. This result is crucial for the subsequent analysis and is stated formally in the following corollary.

Corollary (3). [Performance measure accuracy and equilibrium tax enforcement]

Suppose $\lambda<\frac{2}{3}$. Then

$$
\frac{\partial \gamma^{*}}{\partial \phi_{R}}<0 \quad \text { and } \quad \frac{\partial \gamma^{*}}{\phi_{S}}>0 .
$$

Proof. Follows directly from Proposition 2 by taking partial derivatives.

Corollary 3 shows the two countervailing effects of asymmetric information inside the firm on optimal tax enforcement.

A less accurate performance measure $R$ for the quantity task (i.e. a higher $\sigma_{R}^{2}$ ) will lower optimal enforcement $\gamma^{*}$. This is in line with our finding from Corollary 2 (i) above: When the quantity effort $e_{R}$ is costly to incentivize because it is difficult to measure, enforcement will be less effective at reducing the quantity effort, and so the equilibrium level of enforcement $\gamma^{*}$ will be lower.

By contrast, equilibrium enforcement $\gamma^{*}$ increases in $\phi_{S}=1+\eta \sigma_{S}^{2}$. This means that as the quality or sophistication task becomes more costly to incentivize for the firm-owner due to a less accurate performance measure $S$ (i.e. a higher $\sigma_{S}^{2}$ ), the tax authority's optimal enforcement policy choice $\gamma^{*}$ increases. Again, this corresponds to Cororally 2 (ii) above: Agency frictions in the quality task $e_{S}$ make enforcement more effective, as they make it more costly for the firm-owner to respond to enforcement by incentivizing the agent to pursue sophisticated means of tax evasion.

The observations formalized in Corollary 3 provide the intuition for the following analysis. We ask how the unobservability of efforts and the resulting secondbest nature of the tax evasion contract between firm-owner and tax manager influence the tax authority's enforcement policy compared to the first-best case where efforts are observable and the contract between firm-owner and tax manager is not distorted by the tax manager's private information. Denote by $\gamma^{F B}$ 
the tax authority's equilibrium policy choice when the firm-owner can observe the tax manager's effort choices, so that their contract is a first-best contract. We want to know how the tax authority's second-best policy choice $\gamma^{*}$ relates to $\gamma^{F B}$. Therefore, we deduce the effect of agency frictions between a firm-owner and her tax manager on the government's tax enforcement policy.

Corollary (4). [Observability of efforts and equilibrium enforcement policy] Suppose that $\lambda<\frac{2}{3}$. Then

$$
\gamma^{*}>\gamma^{F B} \quad \text { if and only if } \quad \phi_{R}<\frac{\phi_{S}+\rho \phi_{S}}{1+\rho \phi_{S}} \quad \text {, where } \rho=\frac{(1-\lambda) g}{(2-3 \lambda) \tau^{2}} .
$$

Proof. See appendix A.4.

According to Corollary 3 above, there are two countervailing effects of the agent's private information on the tax authority's equilibrium policy choice. On the one hand, enforcement becomes less effective due to the tax manager's private information in the quantity dimension. But, on the other hand, enforcement becomes more effective due to private information in the quality dimension.

Corollary 4 provides the condition that decides which of these effects dominates when we compare the optimal second-best policy $\gamma^{*}$ to the optimal tax enforcement policy in the first-best situation with observable efforts.

If efforts are unobservable, both dimensions of effort become more costly to incentivize because of inefficient risk sharing in the second-best contract. The extent of these effects is captured by the levels of $\phi_{R}$ and $\phi_{S}$. If $\phi_{S}$ is sufficiently much larger than $\phi_{R}$ so that the condition in Corollary 4 is satisfied, equilibrium enforcement $\gamma^{*}$ in second best is stricter than in the full information case $\gamma^{F B}$. The following figure illustrates how the relative sizes of $\phi_{R}$ and $\phi_{S}$ impact the tax authority's choice of optimal tax enforcement for given parameters $g, \lambda$, and $\tau$. 


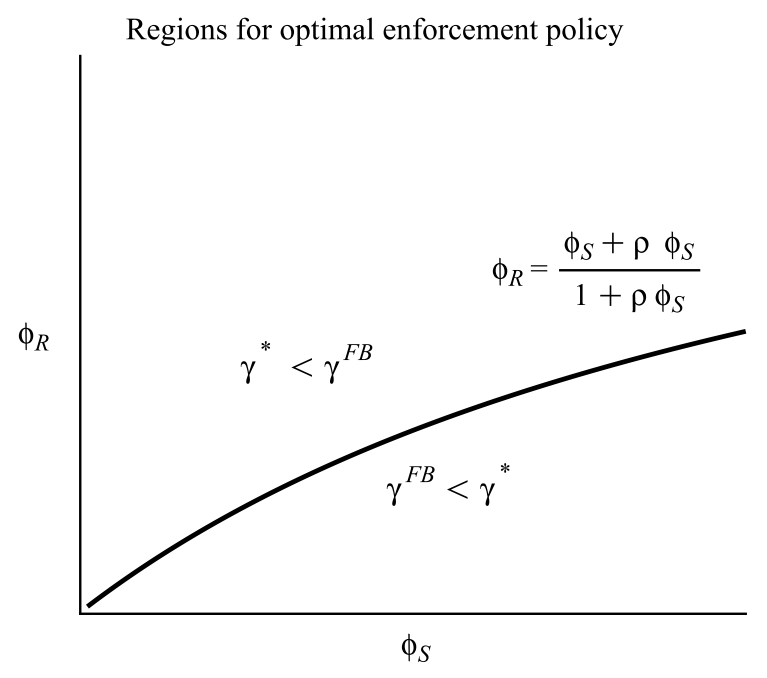

The concave curve in the above figure depicts the equilibrium level of enforcement chosen by the tax authority when efforts are observable, as it passes through the origin, which represents this first best case. As $\phi_{S}$ and $\phi_{R}$ rise from the origin in proportions along this curve, that is the performance measures $R$ and $S$ become less accurate in these proportions, the optimal tax enforcement policy does not change. This is because the two opposing effects of the tax manager's private information on tax enforcement policy described in Corollary 3 exactly cancel each other out, leaving us with $\gamma^{*}=\gamma^{F B}$. If $\phi_{S}$ relative to $\phi_{R}$ rises by more than the proportions along the curve, optimal tax enforcement in equilibrium will be in the region below this curve and therefore stricter than if efforts were observable. Similarly, the region above the curve (but below the $45^{\circ}$-line) contains the combinations $\left(\phi_{S}, \phi_{R}\right)$ for which optimal tax enforcement policy in second best is less strict when the firm-owner cannot observe the tax manager's effort.

Our result stands in stark contrast to the existing literature. Crocker and Slemrod (2005) find that agency frictions inside the firm unambiguously lower the effectiveness of tax enforcement directed at the firm-owner. If enforcement is costly, this implies a lower level of tax enforcement as a result of asymmetric information inside the firm. We find that this effect of lowering enforcement effectiveness is reversed, exactly cancelled out, or at least mitigated by a second, counteracting effect which enhances enforcement effectiveness: Agency frictions 
due to contracting inside the firm impede the firm-owner's ability to respond to stricter enforcement by evading in a more sophisticated, unpunishable way instead of lowering the quantity evaded.

In particular, Corollary 4 shows that if sophisticated means of tax avoidance are much less understandable, and hence less measurable, to the non-specialist firm-owner than the amount of tax reductions claimed in an unsophisticated manner, the effect of principal-agent contracting in corporate tax evasion is to make tax enforcement more effective, rather than less effective as previously thought.

\section{Conclusion}

This paper investigates the optimal enforcement policy that a tax authority chooses to fight corporate tax evasion when such evasion activities take place in a principal-agent setting. Pioneered by Crocker and Slemrod (2005) and Chen and Chu (2005), this approach accounts for the fact that firm-owners are often less informed about the specifics of tax management than the specialist tax managers they employ to reduce a company's tax burden. In contrast to the existing literature, we assume a firm's tax evasion activities to consist of two dimensions, quantity and quality, and argue that these dimensions are affected by informational asymmetries to different extents. A higher quality of tax evasion reduces the firm's expected fine for tax evasion. But highly sophisticated tax evasion schemes are difficult to understand for a non-specialist shareholder, thus the quality dimension might be where the informational asymmetry is largest. We analyze a multitasking model to allow for different levels of agency effects and find that tax enforcement may become more effective as a result of principalagent contracting in firms because the firm chooses not only to evade less but also evades in a less sophisticated way due to asymmetric information. This suggests a stricter optimal corporate tax enforcement policy where firms enter principal-agent relationships to evade taxes, rather than a more lenient one as suggested by the earlier literature. 


\section{References}

Allingham, M. G., Sandmo, A., 1972. Income tax evasion: a theoretical analysis. Journal of Public Economics 1 (3-4), 323-338.

Andreoni, J., Erard, B., Feinstein, J., 1998. Tax compliance. Journal of economic literature $36,818-860$.

Armstrong, C. S., Blouin, J. L., Larcker, D. F., 2012. The incentives for tax planning. Journal of Accounting and Economics 53 (1), 391-411.

Bayer, R., Cowell, F., 2009. Tax compliance and firms' strategic interdependence. Journal of public economics 93 (11), 1131-1143.

Biswas, R., Marchese, C., Privileggi, F., 2012. Firm's tax evasion in a principalagent model with self-protection. Journal of Economics, 1-16.

Bolton, P., Dewatripont, M., 2005. Contract theory. MIT press.

Buergin, R., Vina, G., 2013. G-20 'determined' to fight profit-shifting, secure revenue base. Bloomberg.com (accessed 25 September 2013).

Chen, K., Chu, C., 2005. Internal control versus external manipulation: a model of corporate income tax evasion. Rand Journal of Economics 36 (1), 151-164.

Cowell, F., 2004. Sticks and carrots in enforcement. The Crisis in Tax Administration. Brookings Institution Press, Washington, DC.

Crocker, K. J., Slemrod, J., 2005. Corporate tax evasion with agency costs. Journal of Public Economics 89, 1593-1610.

Desai, M. A., Dharmapala, D., 2006. Corporate tax avoidance and high-powered incentives. Journal of Financial Economics 79, 145-179.

Dewatripont, M., Jewitt, I., Tirole, J., 2000. Multitask agency problems: Focus and task clustering. European Economic Review 44 (4), 869-877.

Drucker, J., 2010. Google 2.4 rate shows how 60 billion lost to tax loopholes. Bloomberg.com (accessed 25 September 2013).

Dyreng, S. D., Hanlon, M., Maydew, E. L., 2010. The effects of executives on corporate tax avoidance. The Accounting Review 85 (4), 1163-1189. 
Ehrlich, I., Becker, G., 1972. Market insurance, self-insurance, and selfprotection. Journal of political Economy 80, 623-648.

Feinstein, J. S., 1991. An econometric analysis of income tax evasion and its detection. The RAND Journal of Economics 22, 14-35.

Goerke, L., Runkel, M., 2011. Tax evasion and competition. Scottish Journal of Political Economy 58 (5), 711-736.

Hanlon, M., Heitzman, S., 2010. A review of tax research. Journal of Accounting and Economics 50 (2), 127-178.

Holmstroem, B., 1979. Moral hazard and observability. The Bell Journal of Economics, 74-91.

Holmstroem, B., Milgrom, P., 1987. Aggregation and linearity in the provision of intertemporal incentives. Econometrica: Journal of the Econometric Society, 303-328.

Holmstroem, B., Milgrom, P., 1991. Multitask principal-agent analyses: Incentive contracts, asset ownership, and job design. JL Econ. \& Org., 24.

Jensen, M. C., Meckling, W. H., 1976. Theory of the firm: Managerial behavior, agency costs and ownership structure. Journal of financial economics 3 (4), $305-360$.

Kocieniewski, D., 2011. G.e.'s strategies let it avoid taxes altogether. www.nytimes.com (accessed 25 September 2013).

Laffont, J.-J., Martimort, D., 2001. The theory of incentives: the principal-agent model. Princeton University Press.

Laffont, J.-J., Tirole, J., 1991. Provision of quality and power of incentive schemes in regulated industries. Equilibrium Theory and Applications: Proceeding of the Sixth International in Economic Theory and Econometrics, $161-193$.

Lee, K., 2001. Tax evasion and self-insurance. Journal of Public Economics 81, $73-81$.

Minnick, K., Noga, T., 2010. Do corporate governance characteristics influence tax management? Journal of corporate finance 16 (5), 703-718. 
Nur-tegin, K. D., 2008. Determinants of business tax compliance. The BE Journal of Economic Analysis \& Policy 8 (1).

OECD, 2013. Addressing base erosion and profit shifting. OECD Publishing. URL http://dx.doi.org/10.1787/9789264192744-en

Reinganum, J. F., Wilde, L. L., 1985. Income tax compliance in a principalagent framework. Journal of Public Economics 26 (1), 1-18.

Skinner, J., Slemrod, J., 1985. An economic perspective on tax evasion. National Tax Journal 38 (3), 345-353.

Slemrod, J., 2004. The economics of corporate tax selfishness. National Tax Journal 57, 877-899.

Slemrod, J., 2007. Cheating ourselves: The economics of tax evasion. The journal of economic perspectives 21 (1), 25-48.

Slemrod, J., Sorum, N., 1984. The compliance cost of the u.s. individual income tax system. National Tax 37, 461-474.

Slemrod, J., Yitzhaki, S., 2002. Tax avoidance, evasion, and administration. Handbook of public economics 3, 1423-1470. 


\section{Appendix}

\section{A.1 Proof of Proposition 1}

We begin with the tax manager's problem. The agent chooses efforts $e_{R}, e_{S}$ to solve

$$
\max _{e_{R}, e_{S}} \quad \alpha+\beta_{R} e_{R}+\beta_{S} e_{S}-\frac{1}{2} e_{R}^{2}-\frac{1}{2} e_{S}^{2}-\frac{\eta}{2}\left(\beta_{R}^{2} \sigma_{R}^{2}+\beta_{S}^{2} \sigma_{S}^{2}\right)
$$

The first-order conditions for the agent's problem are given by

$$
\text { w.r.t. } \quad e_{R}: \quad \beta_{R}-e_{R}=0
$$

and

$$
\text { w.r.t. } \quad e_{S}: \quad \beta_{S}-e_{S}=0
$$

which since both equations are linear in $e_{R}$ and $e_{S}$ respectively has the unique solution

$$
\left(e_{R}^{*}, e_{S}^{*}\right)=\left(\beta_{R}, \beta_{S}\right)
$$

Since the agent's objective function is strictly concave in $e_{R}$ and $e_{S}$ (negative definite Hessian), $\left(e_{R}^{*}, e_{S}^{*}\right)=\left(\beta_{R}, \beta_{S}\right)$ is the unique maximum.

Now consider the principal's problem. The agent's participation constraint $(P C)$ is binding at the optimum, for if it were not, the principal could marginally lower $\alpha, \beta_{R}$, or $\beta_{S}$ (or any linear combination thereof) to increase her profits while still satisfying $(P C)$. Replacing the incentive compatibility constraint $(I C)$ by the agent's unique optimal effort choice $\left(e_{R}^{*}, e_{S}^{*}\right)=\left(\beta_{R}, \beta_{S}\right)$, the principal's unconstrained maximization problem becomes

$$
\max _{\beta_{R}, \beta_{S}} I-\tau\left(I-\beta_{R}\right)-\gamma \tau\left(\beta_{R}-\beta_{S}\right)-\frac{1}{2}\left(\beta_{R}^{2}+\beta_{S}^{2}\right)-\frac{\eta}{2}\left(\beta_{R}^{2} \sigma_{R}^{2}+\beta_{S}^{2} \sigma_{S}^{2}\right)
$$

The first-order conditions for the principal's problem are given by

$$
\text { w.r.t. } \quad \beta_{R}: \quad \tau-\gamma \tau-\beta_{R}-\eta \sigma_{R}^{2} \beta_{R}=0
$$

and

$$
\text { w.r.t. } \beta_{S}: \quad \gamma \tau-\beta_{S}-\eta \sigma_{S}^{2} \beta_{S}=0
$$


which since both equations are linear in $\beta_{R}$ and $\beta_{S}$ respectively has the unique solution

$$
\left(\beta_{R}^{*}, \beta_{S}^{*}\right)=\left(\frac{(1-\gamma) \tau}{1+\eta \sigma_{R}^{2}}, \frac{\gamma \tau}{1+\eta \sigma_{S}^{2}}\right) .
$$

The principal's objective function is strictly concave in $\beta_{R}$ and $\beta_{S}$ (negative definite Hessian) and so $\left(\beta_{R}^{*}, \beta_{S}^{*}\right)$ is the unique maximum.

From the binding participation constraint $(P C)$, it follows that

$$
\alpha^{*}=\frac{1}{2}\left(\eta \sigma_{R}^{2}-1\right) \frac{(1-\gamma)^{2} \tau^{2}}{\left(1+\eta \sigma_{R}^{2}\right)^{2}}+\frac{1}{2}\left(\eta \sigma_{S}^{2}-1\right) \frac{\gamma^{2} \tau^{2}}{\left(1+\eta \sigma_{S}^{2}\right)^{2}} .
$$

Finally, plugging $\left(\beta_{R}^{*}, \beta_{S}^{*}\right)$ into the agent's unique best response, we obtain equilibrium efforts as

$$
\left(e_{R}^{*}, e_{S}^{*}\right)=\left(\beta_{R}^{*}, \beta_{S}^{*}\right)=\left(\frac{(1-\gamma) \tau}{1+\eta \sigma_{R}^{2}}, \frac{\gamma \tau}{1+\eta \sigma_{S}^{2}}\right)
$$

\section{A.2 Proof of Corollary 2}

(i)

$$
\frac{\partial}{\partial \sigma_{R}^{2}}\left|\frac{\partial e_{R}^{*}}{\partial \gamma}\right|=\frac{\partial}{\partial \sigma_{R}^{2}}\left|\frac{-\tau}{1+\eta \sigma_{R}^{2}}\right|=-\frac{\tau \eta}{\left(1+\eta \sigma_{R}^{2}\right)^{2}}<0
$$

(ii)

$$
\frac{\partial}{\partial \sigma_{S}^{2}}\left|\frac{\partial e_{S}^{*}}{\partial \gamma}\right|=\frac{\partial}{\partial \sigma_{S}^{2}}\left|\frac{\tau}{1+\eta \sigma_{S}^{2}}\right|=-\frac{\tau \eta}{\left(1+\eta \sigma_{S}^{2}\right)^{2}}<0
$$

\section{A.3 Proof of Proposition 2}

\section{Suppose first that $\lambda \in\left[0, \frac{2}{3}\right)$.}

The first-order condition of the tax authority's problem of choosing $\gamma \in[0,1]$ to maximize $\mathbb{E} W$ is given by

$$
(2-3 \lambda)(1-\gamma) \frac{\tau^{2}}{\phi_{R}}-(2-3 \lambda) \gamma \frac{\tau^{2}}{\phi_{S}}=(1-\lambda) g \gamma
$$


Solving this equation for $\gamma$ yields the unique solution

$$
\gamma^{*}=\frac{\phi_{S}}{\phi_{S}+\phi_{R}+\frac{(1-\lambda) g}{(2-3 \lambda) \tau^{2}} \phi_{R} \phi_{S}}
$$

The second-order condition for $\gamma^{*}$ to be a maximum is given by

$$
-(2-3 \lambda) \frac{\tau^{2}}{\phi_{R}}-(2-3 \lambda) \frac{\tau^{2}}{\phi_{S}}-(1-\lambda) g<0
$$

and rearranging, it is seen that the second-order condition holds if and only if

$$
\lambda<\frac{2+\frac{g}{\tau^{2}} \frac{\phi_{R} \phi_{S}}{\phi_{R}+\phi_{S}}}{3+\frac{g}{\tau^{2}} \frac{\phi_{R} \phi_{S}}{\phi_{R}+\phi_{S}}} \equiv \bar{\lambda}
$$

Thus a sufficient condition for $\gamma^{*}=\frac{\phi_{S}}{\phi_{S}+\phi_{R}+\frac{(1-\lambda) g}{(2-3 \lambda) \tau^{2}} \phi_{R} \phi_{S}}$ to be the optimal choice is

$$
\lambda<\frac{2}{3}
$$

Now suppose $\lambda=\frac{2}{3}$.

Then the government's objective function is obtained by using $\lambda=\frac{2}{3}$ in (7) as

$$
\frac{1}{3}(2-\tau) I-\frac{1}{6} g \gamma^{2}
$$

and so social welfare strictly decreases in $\gamma$ for $\gamma \in[0,1]$.

Therefore, $\gamma^{*}=0$ if $\lambda=\frac{2}{3}$.

Now suppose $\lambda \in\left(\frac{2}{3}, \bar{\lambda}\right)$, where $\bar{\lambda}=\frac{2+\frac{g}{\tau^{2}} \frac{\phi_{R} \phi_{S}}{\phi_{R} \phi_{S}}}{3+\frac{g}{\tau^{2}} \frac{\phi_{R} \phi_{S}}{\phi_{R}+\phi_{S}}}$ as in (14).

Then since $\lambda<\bar{\lambda}$, the tax authority's objective function (7) is strictly concave in $\gamma$ and so the unique maximum of the objective function is found at $\frac{\phi_{S}}{\phi_{S}+\phi_{R}+\frac{(1-\lambda) g}{(2-3 \lambda) \tau^{2}} \phi_{R} \phi_{S}}$. However, one obtains that

$$
\frac{2}{3}<\lambda<\bar{\lambda} \Rightarrow \frac{\phi_{S}}{\phi_{S}+\phi_{R}+\frac{(1-\lambda) g}{(2-3 \lambda) \tau^{2}} \phi_{R} \phi_{S}}<0
$$

and so by the property that a quadratic function has only one extremum, and the government chooses $\gamma \in[0,1]$, it follows that the tax authority's objective function (7) is strictly decreasing on $[0,1]$. Therefore, $\gamma^{*}=0$ if $\lambda \in\left(\frac{2}{3}, \bar{\lambda}\right)$. 
Now suppose $\lambda=\bar{\lambda}=\frac{2+\frac{g}{\tau^{2}} \frac{\phi_{R} \phi_{S}}{\phi_{R}+\phi_{S}}}{3+\frac{g}{\tau^{2}} \frac{\phi_{R} \phi_{S}}{\phi_{R}+\phi_{S}}}$

Then the tax authority's objective function given by (7) is linear in $\gamma$ with negative slope

$$
-\frac{g \tau^{2} \phi_{S}}{g \phi_{R} \phi_{S}+3 \tau^{2}\left(\phi_{R}+\phi_{S}\right)}
$$

as can be seen by plugging $\lambda=\bar{\lambda}$ into (7) and taking the derivative of the resulting expression with respect to $\gamma$. Since welfare is strictly decreasing in $\gamma$, it follows that $\gamma^{*}=0$ is the optimal choice when $\lambda=\bar{\lambda}$.

Finally, suppose $\lambda \in(\bar{\lambda}, 1]$.

Then the government's objective function (7) is strictly convex in $\gamma$, and so $\frac{\phi_{S}}{\phi_{S}+\phi_{R}+\frac{(1-\lambda) g}{(2-3 \lambda) \tau^{2}} \phi_{R} \phi_{S}}$ marks the global minimum of the objective function (7). This implies that the maximum $\gamma^{*}$ has to be a corner solution, i.e. either $\gamma^{*}=0$ or $\gamma^{*}=1$. Since the objective function (7) is quadratic in $\gamma$, we know it is symmetric about its minimum. Since $\gamma \in[0,1]$, symmetry implies that $\gamma^{*}=0$ is the optimal choice if the minimum is found to the right of $\gamma=\frac{1}{2}$, i.e. when

$$
\frac{\phi_{S}}{\phi_{S}+\phi_{R}+\frac{(1-\lambda) g}{(2-3 \lambda) \tau^{2}} \phi_{R} \phi_{S}}>\frac{1}{2}
$$

This is equivalent to

$$
\phi_{S}-\phi_{R}>\frac{(1-\lambda) g}{(2-3 \lambda) \tau^{2}} \phi_{R} \phi_{S}
$$

And since we assumed $\sigma_{S}^{2}>\sigma_{R}^{2}$, the left hand side of this inequality is positive while the right hand side is negative (recall that $\lambda>\frac{2}{3}$ ) and so this inequality always holds. So we have $\gamma^{*}=0$ for $\lambda \in(\bar{\lambda}, 1]$.

\section{A.4 Proof of Corollary 3}

We first derive the equilibrium tax enforcement policy $\gamma^{F B}$ chosen by the tax authority when the tax manager's efforts $e_{R}$ and $e_{S}$ are observable to the firmowner. Recall from (1) that the first best effort levels induced in this case are given by

$$
e_{R}^{F B}=(1-\gamma) \tau \quad \text { and } \quad e_{S}^{F B}=\gamma \tau
$$


Using $e_{R}^{F B}$ and $e_{S}^{F B}$ in the social welfare function from (4), we obtain the tax authority's problem in first-best as

$\max _{\gamma}\left\{\lambda I+(1-2 \lambda) \tau I-\frac{1}{2}(2-3 \lambda)(1-\gamma)^{2} \tau^{2}-\frac{1}{2}(2-3 \lambda) \gamma^{2} \tau^{2}-(1-\lambda) \frac{1}{2} g \gamma^{2}\right\}$

This problem is strictly concave in $\gamma$ and has the unique solution

$$
\gamma^{F B}=\frac{1}{2+\frac{(1-\lambda) g}{(2-3 \lambda) \tau^{2}}} .
$$

Comparing $\gamma^{F B}$ to the second-best optimal enforcement intensity $\gamma^{*}$ when $\lambda<\frac{2}{3}$ stated in Proposition 2 gives

$$
\gamma^{*}=\frac{\phi_{S}}{\phi_{S}+\phi_{R}+\frac{(1-\lambda) g}{(2-3 \lambda) \tau^{2}} \phi_{R} \phi_{S}}>\frac{1}{2+\frac{(1-\lambda) g}{(2-3 \lambda) \tau^{2}}}=\gamma^{F B}
$$

if and only if

$$
\phi_{S}+\phi_{R}+\frac{(1-\lambda) g}{(2-3 \lambda) \tau^{2}} \phi_{R} \phi_{S}<\phi_{S}\left(2+\frac{(1-\lambda) g}{(2-3 \lambda) \tau^{2}}\right)
$$

if and only if

$$
\phi_{R}<\frac{\phi_{S}+\frac{(1-\lambda) g}{(2-3 \lambda) \tau^{2}} \phi_{S}}{1+\frac{(1-\lambda) g}{(2-3 \lambda) \tau^{2}} \phi_{S}}
$$

